Available online on 15.7.2018 at http://ujpr.org
Universal Journal of Pharmaceutical Research
An International Peer Reviewed Journal
Open access to Pharmaceutical research

\title{
PREVALENCE OF METHICILLIN RESISTANT STAPHYLOCOCCUS AUREUS (MRSA) AND ANTIMICROBIAL SUSCEPTIBILITY PATTERNS AT A PRIVATE HOSPITAL IN SANA'A, YEMEN

\author{
Ali Alyahawi ${ }^{*}$ (D) Ali Alkaf ${ }^{2}$ (D) Abdul Monem Alhomidi ${ }^{3}$ (D) \\ ${ }^{I}$ Department of Pharmacy, Faculty of Medical Sciences, Al-Razi University, Republic of Yemen. \\ ${ }^{2}$ Faculty of Pharmacy, Sana'a University, Republic of Yemen. \\ ${ }^{3}$ Faculty of Medicine, Sana'a University, Republic of Yemen.
}

\section{ABSTRACT}

Objective: Methicillin resistant Staphylococcus aureus (MRSA) strains are common causes of nosocomial infections and are associated with increased morbidity and mortality. In addition, the antibiotic resistance for MRSA is a major concern in clinical practice. To study the prevalence and the antimicrobial susceptibility pattern of MRSA isolates from patients in a private hospital. Methods: The study was performed at a private hospital in Sana'a, Yemen. All the patients' samples from January, 2017 to December, 2017 were included. All isolates from inpatients' clinical specimens (mainly respiratory secretion, pus, urine, and blood) were collected and standard isolation procedures were applied to all the samples. The records were taken from the microbiology department. Antibiotic susceptibility testing was done by Kirby Bauer's Disc diffusion technique, following the national committee for clinical laboratory standards. The antimicrobial susceptibility patterns of all the MRSA strains were studied against several antibiotics.

Results: A total of 2079 samples were gathered during the study period. Among them, 199 strains of Staphylococcus aureus were isolated. A majority of Staphylococcus aureus isolates were from pus specimen $(\mathrm{n}=81 / 199 ; 40.7 \%)$. MRSA prevalence among the patients was $17.6 \%(n=35 / 199 ; 17.6)$. Highest proportion of MRSA was in ICU and surgical departments about $29 \%$ of all MRSA isolates. A majority of MRSA isolates were from sputum specimen $(n=18 / 35 ; 51.4 \%)$. The study findings showed that MRSA isolates had the highest frequency of resistant $(100 \%)$ to levofloxacin and amoxicillin/clavulinic acid, followed by ciprofloxacin $97 \%$, gentamicin and ampicillin/ sulbactam $94 \%$, cefuroxime $91 \%$, moxifloxacin 76\%, erythromycin $71.5 \%$, clindamycin $70.5 \%$, and imipenem 55\%. The highest frequency of sensitivity (100\%) was observed with linezolide, vancomycin, and trimethoprim/ sulfamethoxazole.

Conclusion: In conclusion, MRSA isolates were highly susceptible to newer drugs such as linezolid and to vancomycin which is not a commonly prescribed drug due to the higher nephrotoxic antibiotic. A more careful monitoring for use of broad-spectrum antibiotics should be instituted.

Keywords: Antimicrobial susceptibility, MRSA, prevalence, vancomycin.

Article Info: Received 2 May 2018; Revised 4 June; Accepted 30 June, Available online 15 July 2018

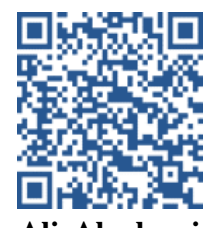

\section{Cite this article-}

Ali A, Ali A, Alhomidi AM. Prevalence of methicillin resistant Staphylococcus aureus (MRSA) and antimicrobial susceptibility patterns at a private hospital in Sana'a, Yemen. Universal Journal of Pharmaceutical Research 2018; 3(3): 4-9.

DOI: https://doi.org/10.22270/ujpr.v3i3.159

Address for Correspondence:

Ali Alyahawi, Department of Pharmacy, College of Medical and Health Sciences, Al-Razi University, Republic of Yemen. E-mail: alyahawipharm@yahoo.com

\section{INTRODUCTION}

Staphylococcus aureus is one of the most important pathogens affecting humans. Penicillin is the drug of choice to treat infections caused by Staphylococcus aureus. Because of the penicillin was commonly prescribed drugs, the prevalence of penicillin resistant strains increased, especially in hospitals ${ }^{1}$. MRSA was first described in 1961. It was reported after one year of introduction of methicillin. Recently, it was defined as one of the most important nosocomial pathogens. New studies suggest that the infection due to MRSA is not only hospital-acquired but community acquired as well $^{2}$. Also MRSA has become a major public health problem worldwide ${ }^{3}$. Some large outbreaks of MRSA have been documented from different regions of the world, where it had caused severe infections including septicemia, endocarditis and meningitis ${ }^{4}$. A study by Dickinson in England and Wales has approved an increase in the death rate of MRSA infection ${ }^{5}$. The risk factors that increase in MRSA prevalence are 
antibiotics abuse, prolonged hospitalization, intravascular instrumentation and hospitalization in an intensive care unit. There is significant variation in prevalence of clinical infections among units, hospitals and countries ${ }^{4}$. MRSA is of serious concern because of resistance to many other antimicrobials that are commonly used in hospitals. Another important element was that emergence of resistance to vancomycin, although at a low level has been documented $^{6}$. Significantly, the Netherlands and countries in the Scandinavian region, had maintained low rates of MRSA infection due to strict infection control practices ${ }^{7}$. The problem of MRSA continues to increase and the rising colonization rates lead to the increasing of infection rates in the public and in hospitals. This can increase hospital stays and greater costs of the health care system ${ }^{8}$. Appropriate selection of empiric antibiotics for infections, depending on local circulating pathogens, can lead to good patient outcomes. So, epidemiologic information collected through ongoing surveillance is important to support clinicians and infection control committees to prevent and treat infection ${ }^{7}$.The hospitals of different sizes were facing the problem of MRSA. In addition, the problem of MRSA appears to be increasing regardless the size of hospital and its control measures for MRSA $^{8}$. The aim of the present study is the detection of MRSA from various clinical departments at a local private hospital in Sana'a, Yemen and determining their susceptibility to some antimicrobial agents.

\section{METHODS}

The current retrospective study based on electronic laboratory records of Staphylococcus aureus isolates and MRSA isolates from clinical specimens analyzed at microbiology laboratory of university of sciences and technology (UST) hospital in Sana'a, Yemen. The records were taken from the microbiology department. Staphylococcus strains were identified based on Gram's stain morphology, colony characteristics, and biochemical identification tests. All isolates were identified as $S$. aureus according to standard methods ${ }^{9}$. A total of 2079 isolates were collected from the hospitalized patients in hospital of UST from January 2017 to December 2017. These isolates were obtained through conventional clinically oriented ordered cultures. From 2079 isolates, a total of 199 isolates were $S$. aureus strains. Methicillin resistance was determined using methicillin screening. All isolates were from inpatients' clinical specimens (mainly respiratory secretion, pus, urine, and blood) and Standard isolation procedures were applied to all the samples. Antibiotic susceptibility testing was done by Kirby Bauer's Disc diffusion technique, following Clinical and Laboratory Standards Institute (CLSI) ${ }^{9}$. The antimicrobial susceptibility patterns of all the MRSA strains were determined against the following antibiotics: vancomycin, linezolide, imipenem, levofloxacin, ciprofloxacin, cotrimoxzole, Erythromycinamoxicillin/clavulinic Acid, cefuroxime, doxycycline, clindamycin, ampicillin/sulbactam, gentamicin, moxifloxacin, and lincomycin. Full ethical clearance was obtained from the qualified authorities who approved the study design. All data were analyzed using SPSS Statistics 21. Data was presented in tables and graphs.

\section{RESULTS}

The Figure 1 showed highest numbers of Staphylococcus aureus were obtained from pus $(n=81 / 199 ; 40.7 \%)$ and least from urine $(n=11 / 199$; $5.5 \%$ ). In this study, overall MRSA prevalence was $17.6 \%(n=35 / 199 ; 17.6)$.

Table 1: The antibiotic susceptibility pattern for MRSA isolates.

\begin{tabular}{|c|c|c|c|c|c|c|c|}
\hline \multirow[t]{2}{*}{ Antibiotic } & \multirow{2}{*}{$\begin{array}{c}\text { Expected } \\
\text { options }\end{array}$} & \multicolumn{2}{|c|}{ Response } & \multirow[t]{2}{*}{ Antibiotic } & \multirow{2}{*}{$\begin{array}{c}\text { Expected } \\
\text { options }\end{array}$} & \multicolumn{2}{|c|}{ Response } \\
\hline & & $\mathbf{F}$ & $\%$ & & & $\mathbf{F}$ & $\%$ \\
\hline \multirow{3}{*}{ Imipenem } & S & 10 & 30 & \multirow[t]{3}{*}{ Moxifloxacin } & S & 0 & 00 \\
\hline & $\mathrm{R}$ & 18 & 55 & & $\mathrm{R}$ & 25 & 76 \\
\hline & I & 5 & 15 & & I & 8 & 24 \\
\hline \multirow{3}{*}{$\begin{array}{c}\text { Amoxicillin/ } \\
\text { Clavulinic Acid }\end{array}$} & S & 0 & 00 & \multirow[t]{3}{*}{ Gentamicin } & S & 2 & 6 \\
\hline & $\mathrm{R}$ & 33 & 100 & & $\mathrm{R}$ & 32 & 94 \\
\hline & I & 0 & 00 & & I & 0 & 00 \\
\hline \multirow{3}{*}{$\begin{array}{l}\text { Ampicillin/ } \\
\text { Sulbactam }\end{array}$} & S & 1 & 6 & \multirow[t]{3}{*}{ Clindamycin } & $\mathrm{S}$ & 10 & 29.5 \\
\hline & $\mathrm{R}$ & 16 & 94 & & $\mathrm{R}$ & 24 & 70.5 \\
\hline & I & 0 & 00 & & I & 0 & 00 \\
\hline \multirow{3}{*}{ Cefuroxime } & $S$ & 3 & 9 & \multirow[t]{3}{*}{ Levofloxacin } & S & 0 & 00 \\
\hline & $\mathrm{R}$ & 31 & 91 & & $\mathrm{R}$ & 35 & 100 \\
\hline & I & 0 & 00 & & I & 0 & 00 \\
\hline \multirow[t]{3}{*}{ Erythromycin } & $\mathrm{S}$ & 10 & 28.5 & \multirow{3}{*}{$\begin{array}{c}\text { Trimethoprim/ } \\
\text { Sulfamethoxazole }\end{array}$} & $\mathrm{S}$ & 35 & 100 \\
\hline & $\mathrm{R}$ & 25 & 71.5 & & $\mathrm{R}$ & 0 & 00 \\
\hline & I & 0 & 00 & & I & 0 & 0.0 \\
\hline \multirow[t]{3}{*}{ Ciprofloxacin } & $\mathrm{S}$ & 1 & 3 & \multirow[t]{3}{*}{ Linezolid } & $\mathrm{S}$ & 31 & 100 \\
\hline & $\mathrm{R}$ & 33 & 97 & & $\mathrm{R}$ & 0 & 00 \\
\hline & I & 0 & 00 & & I & 0 & 00 \\
\hline \multirow[t]{3}{*}{ Doxycycline } & $\mathrm{S}$ & 2 & 5.8 & \multirow[t]{3}{*}{ Vancomycin } & $S$ & 35 & 100 \\
\hline & $\mathrm{R}$ & 31 & 91.2 & & $\mathrm{R}$ & 0 & 00 \\
\hline & I & 1 & 3 & & I & 0 & 00 \\
\hline
\end{tabular}




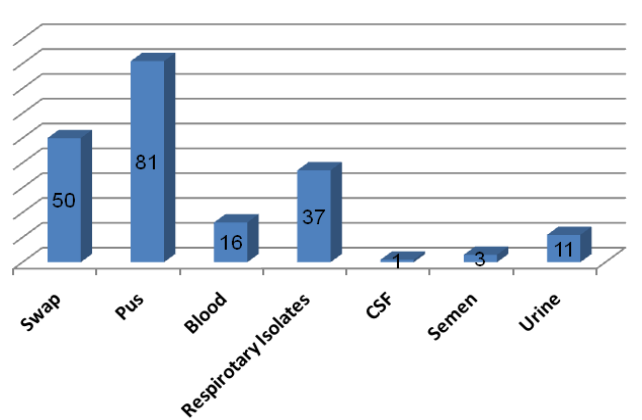

Figure 1: Distribution of $S$. aureus according to sample types.

The study results showed that the most of the MRSA isolates prevalence in age group between 46 to 60 years about $12(34 \%)$, followed by the age more than 60 years in second rank about $8(23 \%)$, and finally the age between 1 to 15 or years only about $2(6 \%)$.

Table 2: The sensitivity pattern of vancomycin and Linezolide within age group.

\begin{tabular}{|c|c|c|c|c|}
\hline \multirow[t]{2}{*}{ Age group } & \multicolumn{3}{|c|}{ Vancomycin } & \multirow{2}{*}{$\begin{array}{l}\text { The level of } \\
\text { (P value) }\end{array}$} \\
\hline & $\mathbf{S}$ & $\mathbf{R}$ & I & \\
\hline $1-15$ years & 2 & 0 & 0 & \multirow{5}{*}{0.74} \\
\hline 16 - 30 years & 6 & 0 & 0 & \\
\hline 31 - 45 years & 7 & 0 & 0 & \\
\hline 46 - 60 years & 11 & 0 & 0 & \\
\hline $\begin{array}{l}\text { More than } 60 \\
\text { years }\end{array}$ & 8 & 0 & 0 & \\
\hline \multicolumn{5}{|c|}{ Linezolide } \\
\hline $1-15$ years & 2 & 0 & 0 & \multirow{5}{*}{0.44} \\
\hline 16 - 30 years & 6 & 0 & 0 & \\
\hline $31-45$ years & 7 & 0 & 0 & \\
\hline 46 - 60 years & 10 & 0 & 0 & \\
\hline $\begin{array}{l}\text { More than } 60 \\
\text { years }\end{array}$ & 6 & 0 & 0 & \\
\hline
\end{tabular}

The Figure 3 showed that the most of the MRSA isolates were in male about $29(83 \%)$, whereas the female participants only about $6(17 \%)$. According to the study findings, ICU and surgical departments had the same and most prevalence of MRSA about $10(29 \%)$, followed by the medical and laboratory departments with rank about $6(17 \%)$, and finally the neurological department only about 3(8\%).

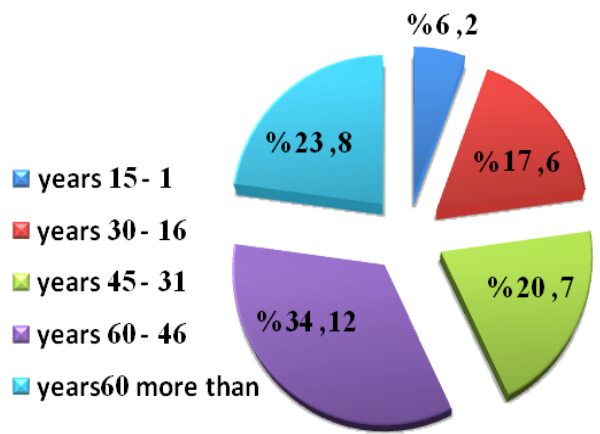

Figure 2: Distribution of MRSA isolates according to age group.
The Figure 5 showed that more than half of MRSA isolates from sputum culture about 18(51.4\%), followed by the wound swab culture about $12(34.3 \%)$, and finally blood culture only about $2(5.7 \%)$.

In this study, the most of medication that had resistance to MRSA test were about 12 drugs $(80 \%)$, whereas the medication that sensitive to MRSA test about 3 drugs (20\%). Also the study results showed that MRSA isolates were resistant to levofloxacin $100 \%$, amoxicillin/clavulinic acid100\%, moxifloxacin $76 \%$, gentamicin $94 \%$, clindamycin $70.5 \%$, ciprofloxacin $97 \%$, cefuroxime $91 \%$ erythromycin $71.5 \%$, and ampicillin/sulbactam $94 \%$. The highest frequency of sensitivity $(100 \%)$ was observed with trimethoprim/ sulfamethoxazole, linezolide, and Vancomycin (Table1). The Table 2 showed there were no statistical significant relationship between the usage of vancomycin and linezolid age group $(\mathrm{P}$ value $=0.74$, 0.44). The Table 3 showed there were no statistical significant relationship between the sensitivity pattern of vancomycin and linezolid hospital department $(P$ value $=0.63,0.35$ ).

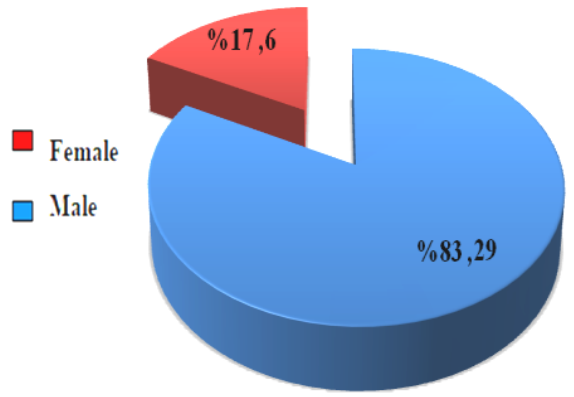

Figure 3: Distribution of MRSA isolates according to gender.

Also the study findings showed that there was no statistical significant relationship between the sensitivity pattern of vancomycin and linezolide and sample type $(\mathrm{P}$ value $=0.80,0.23)$.

\section{DISCUSSION}

Recently, the prevalence of MRSA has steadily increased worldwide ${ }^{4}$. In addition, the antimicrobial susceptibility pattern of MRSA strains should be described. In current study, most $S$. aureus strains $(\mathrm{n}=81 / 199 ; 40.7 \%)$ were isolated from pus specimen. This is consistent with a previous study done in Nairobi ${ }^{10}$.

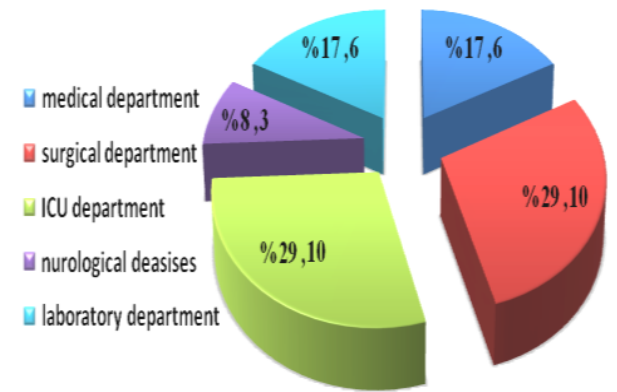

Figure 4: Distribution of MRSA isolates according to hospital departments. 
Table 3: The sensitivity pattern of vancomycin and linezolide within hospital department.

\begin{tabular}{|c|c|c|c|c|}
\hline \multirow[t]{2}{*}{ Hospital Department } & \multicolumn{3}{|c|}{ Vancomycin } & \multirow{2}{*}{$\begin{array}{l}\text { The level of } \\
\text { (P value) }\end{array}$} \\
\hline & $\mathbf{S}$ & $\mathbf{R}$ & $\mathbf{I}$ & \\
\hline Medical department & 6 & 0 & 0 & \\
\hline Surgical department & 10 & 0 & 0 & \\
\hline ICU department & 9 & 0 & 0 & 0.63 \\
\hline Neurological diseases & 3 & 0 & 0 & \\
\hline Laboratory department & 6 & 0 & 0 & \\
\hline Hospital Department & \multicolumn{3}{|c|}{ Linezolide } & \\
\hline Medical department & 5 & 0 & 0 & 0.35 \\
\hline Surgical department & 10 & 0 & 0 & \\
\hline ICU department & 8 & 0 & 0 & \\
\hline Neurological diseases & 2 & 0 & 0 & \\
\hline Laboratory department & 6 & 0 & 0 & \\
\hline
\end{tabular}

In a study done to determine the antimicrobial susceptibility pattern of $S$. aureus strains isolated from hospitalized patients in Iran, most of the isolates were from blood specimens $(29 \%)^{11}$. Another study done on prevalence and antibiotic susceptibility pattern of $S$. aureus from clinical isolates in Nigeria showed a majority of the isolates were from urine specimens $(76 \%)^{12}$. The high number of $S$. aureus isolated in pus may be attributed to exposure of wounds which makes them more prone to infections and poor hygiene. In this study, overall MRSA prevalence was $17.6 \%$ $(\mathrm{n}=35 / 199 ; 17.6)$. This prevalence was lower than in previous studies that reported $31.5 \%{ }^{13}$ and $46.3 \% 14$.

This difference could be due to various interventions during the study period such as infection control and appropriate antibiotic usage ${ }^{14,15}$. Also MRSA prevalence was higher in studies done in two private hospitals in Nairobi, Kenya, which showed a 3.8\% prevalence ${ }^{16}$. In addition, a study in Eritrea reported $0.03 \%$ of prevalence in Dutch hospitals ${ }^{(17)}$. This approved there is high variance of MRSA prevalence from different countries. The low prevalence of MRSA in private hospitals could be attributed to better infection controls ${ }^{14}$.

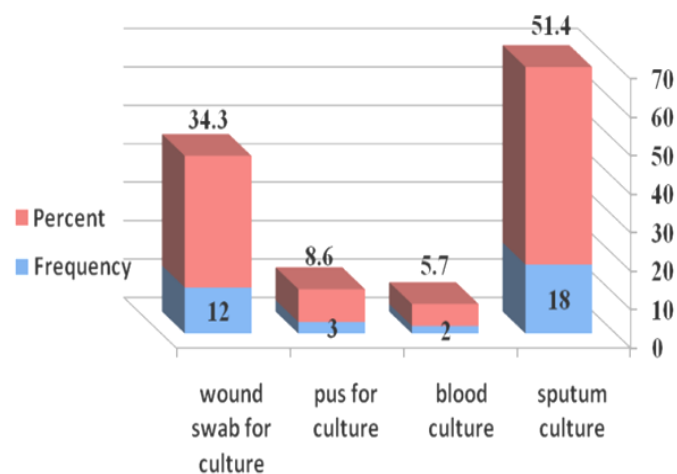

Figure 5: Distribution of MRSA isolates according to sample test.

According to current study results, majority of MRSA was isolated from sputum specimens, 18/35 (51.4\%). In contrast to study findings in Nigeria ${ }^{6}$, and $\operatorname{Iran}^{11}$ showed different specimens were predominant. This variation in prevalence may be because of several factors like healthcare facilities available in the particular hospital, implementation and monitoring of infection control committee, rationale antibiotic usage which varies from hospital to hospital ${ }^{14,15}$. In this study, $100 \%$ of MRSA isolates were sensitive to vancomycin. This finding is similar to a study done on antimicrobial susceptibility of MRSA in hospitalized patients in Iran, two hospitals in India and two private hospitals in Kenya showed $100 \%$ susceptibility to vancomycin ${ }^{17,18,10}$. On other hand, studies done in $\operatorname{Iran}^{19}$ which showed $5 \%$ of the MRSA isolates were resistant to vancomycin and in a tertiary care hospital in India ${ }^{20}$ and pediatrics and neonatal intensive care patients at Nairobi which respectively showed 3.5 and $1 \%$ resistance to vancomycin among MRSA $^{6}$. Recently, many antibiotics with anti-MRSA activity were introduced to the market, some of which are available in Yemen. Linezolid is among these agents which is not widely available and it is not in use in many Yemeni hospitals including the setting of this study. In the present study, $100 \%$ of MRSA isolates were sensitive to linezolid. Garcia et al., have reported the first clinical outbreak of linezolid resistant $S$. aureus (LRSA) from a tertiary teaching university hospital in Madrid, Spain ${ }^{21}$. In their article they reported 12 patients with LRSA from which 6 patients died (with one death ascribed to LRSA infection). In the last two decades prevalence of MRSA has steadily increased worldwide. Therefore, they stated that this increase was associated with nosocomial transmission and extensive use of this antibiotic ${ }^{22}$.

Table 4: The sensitivity pattern of vancomycin and linezolide within sample type.

\begin{tabular}{|c|c|c|c|c|}
\hline \multirow[t]{2}{*}{ Sample Type } & \multicolumn{3}{|c|}{ Vancomycin } & \multirow[t]{2}{*}{ P-value } \\
\hline & $\mathbf{S}$ & $\mathbf{R}$ & I & \\
\hline Sputum culture & 17 & 0 & 0 & \\
\hline Blood culture & 2 & 0 & 0 & \\
\hline Pus for culture & 3 & 0 & 0 & 0.80 \\
\hline \multirow{2}{*}{$\begin{array}{l}\text { wound swab for } \\
\text { culture }\end{array}$} & 12 & 0 & 0 & \\
\hline & \multicolumn{3}{|c|}{ Linezolide } & \\
\hline Sputum culture & 14 & 0 & 0 & 0.23 \\
\hline Blood culture & 2 & 0 & 0 & \\
\hline Pus for culture & 3 & 0 & 0 & \\
\hline $\begin{array}{l}\text { Wound swab for } \\
\text { culture }\end{array}$ & 12 & 0 & 0 & \\
\hline
\end{tabular}

In this study, the results showed that MRSA isolates were resistant to levofloxacin100\%, amoxicillin/ clavulinic acid $100 \%$, moxifloxacin $76 \%$, gentamicin $94 \%$, clindamycin $70.5 \%$, ciprofloxacin $97 \%$, cefuroxime $91 \%$ erythromycin $71.5 \%$, ampicillin/ sulbactam 94\%, and imipenem 55\%. The highest frequency of sensitivity $(100 \%)$ was observed with trimethoprim/ sulfamethoxazole, linezolide, and vancomycin. Multidrug- resistance made the treatment of MRSA more difficult. This may be due to dispensing antibiotics without prescription and inappropriate selection of antibiotics for infections as empirical treatment worldwide. Also the use of broadspectrum antibiotics for treating infections such as imipenem may be increase the rate of MRSA and other resistant pathogens, so a more careful monitoring of antibiotics should be instituted. Vancomycin is the universally accepted drug of choice. It was found that 
all MRSA isolates to be susceptible to vancomycin. Similar results have been reported by other authors ${ }^{23,24}$. Resistant to quinolones (Levofloxacin, ciprofloxacin, and moxifloxacin) was high (100, 97\%, and 76\%; respectively) in the present study. In a previous study ${ }^{25}$, the resistant rate was also high $(87.5 \%)$, but another study ${ }^{26}$ conducted in 2003, reported the resistant rate of ciprofloxacin to be only $32.6 \%$. The rapid emergence of quinolones was probably due to the indiscriminate empirical use of these drugs. An important finding of the present study was that the MRSA cases from ICU accounted for $17.6 \%$ of all cases. Current finding was in agreement with the findings of Dominique et al., ${ }^{27}$ from Switzerland. Also slightly higher than study conducted in 2003 from Nebal, reported the MRSA cases from ICU were only $10 \%$ from all MRSA cases $^{31}$. A European study on prevalence of MRSA infection on samples from intensive care, estimated close to $65 \%{ }^{28}$. In the present study, the low prevalence of MRSA, which included clinical samples from all hospital wards, illustrated the efficacy of relatively good infection control practice in the study setting. Also maximum resistance was seen with ampicillinsulbactam, amoxicillin-clavulanic and gentamicin (Table 3). Similar results were obtained in a previous study ${ }^{29}$. In addition, resistance was also seen with cefuroxime (91\%), doxycyclin (91.2\%), and erythromycin (71.5\%). Gentamicin is a most commonly used drug, because of its low cost and synergistic activity with beta-lactam antibiotics. In the present study, $94 \%$ of gentamicin resistance was seen, which was slightly higher than a previous study ${ }^{30}$. Most common reason for multidrug resistant MRSA is indiscriminate use of antibiotics without drug sensitivity testing which may be due to lack of advanced laboratory facilities or negligence on the part of medical practitioners or patients poor economic status. Also this is due to the fact that MRSA is often multidrugresistant ${ }^{6}$. Although vancomycin seems to be the only antimicrobial agent who showed $100 \%$ sensitivity and may be used as the drug of choice for treating multidrug-resistant MRSA infections, vancomycin is not a commonly prescribed drug, which is almost due to the higher nephrotoxic antibiotic and its unavailability in many parts of the country. The control of MRSA transmission seems to be the only hope to complete eradication of MRSA. The most effective way to control MRSA is good hand hygiene along with environmental cleaning of hospital rooms to reduce nosocomial rates of infection ${ }^{7}$.The results of current study showed that there were highly susceptible to newer drugs such as linezolid. This finding differs from a study done by Arian poor et al., in Iran which showed $5.5 \%$ of MRSA isolates were resistant to linezolid ${ }^{19}$.

\section{CONCLUSION AND RECOMMENDATIONS}

The present study showed a low level prevalence of MRSA. Also MRSA isolates were highly susceptible to newer drugs such as linezolid and to vancomycin which is not a commonly prescribed drug due to the higher nephrotoxic antibiotic. Also this study showed that ICU and surgical wards had the highest proportion of MRSA isolates of hospital departments. Information from this study may be used in future as a baseline for follow-up to the susceptibility trend of various drugs to be used for the treatment of $S$. aureus infections. Routine screening of MRSA and regular studies should be conducted to predict the trend of MRSA.

\section{AUTHOR'S CONTRIBUTION}

The manuscript was carried out, written, and approved in collaboration with all authors.

\section{ACKNOWLEDGEMENTS}

The authors extend their thanks and appreciation to the Al-Razi University, Republic of Yemen to provide necessary facilities for this work.

\section{CONFLICT OF INTEREST}

The authors declare that they have no competing interests.

\section{REFERENCES}

1. Perwaiz S, Qamaruddin Barakzi Q, Farooqi BJ, Khursheed N, Sabir N. Antimicrobial susceptibility pattern of clinical isolates of methicillin resistant Staphylococcus aureus. Karachi 2007; 57: 1. PMID: 26719783

2. Maple PAC, Hamilton-Miller JMT, Brumfitt W. Worldwide antibiotic resistance in methicillin resistant Staphylococcus aureus. Lancet 1989; 1:537-40. PMID: 25859123

3. Jarvis WR, Schlosser J, Chinn RY, Tweeten S, Jackson, M. National prevalence of methicillin-resistant Staphylococcus aureus in inpatients at US health care facilities. Am. J Infect Control 2007; 35: 631- 637. https://doi.org/10.1016/j.ajic.2012.02.001

4. Kumari N, Mohapatra TM, Singh YI. Prevalence of Methicillin-Resistant Staphylococcus aureus (MRSA) in a Tertiary-Care Hospital. J Nepal Med Assoc 2008; 47(170):53-6. https://doi.org/10.1186/s13756-018-0408-z

5. Dickinson E. Mortality from methicillin-resistant Staphylococcus aureus in England and Wales: analysis of death certificates. BMJ 2002; 325:1390-1. https://doi.org/10.1136/bmj.325.7377.1390

6. MIR BA, Srikanth. Prevalence and antimicrobial susceptibility of methicillin resistant Staphylococcus aureus and Coagulase- Negative Staphylococciina Tertiary Care Hospital. Asian J Pharm Clin Res 2013; 6(3):231234. https://doi.org/10.4103/0972-5229.58542

7. Mejía C, Zurita J, Guzmán-Blanco M. Epidemiology and surveillance of methicillin-resistant Staphylococcus aureus in Latin America. Braz J Infect Dis 2010; 14(2):79-86.

8. Al-Dahbi and Al-Mathkhury. Distribution of Methicillin Resistant Staphylococcus aureus in Iraqi patients and Healthcare Workers. Iraqi J Science 2013; 54 (2):293-300.

9. Performance Standards for Antimicrobial Susceptibility Testing; $20^{\text {th }}$ Informational Supplement, Clinical and Laboratory Standards Institute (CLSI) M100-S20: 30:1: Clinical and Laboratory Standards Institute; 2012.

10. Kanaga EL. Antimicrobial susceptibility of bacteria that cause wound sepsis in the paediatric surgica. Wayne, PA 1 patients at Kenyatta national hospital. 2014; http://erepo sitory.uonbi .ac.ke/handl e/11295/95412. Accessed 7 Sept 2017. https://doi.org/10.9734/IJTDH/2015/16516

11. Soltani R, Khalili H, Rasoolinejad M, Abdollahi A. Antimicrobial susceptibility pattern of Staphylococcus aureus strains isolated from hospitalized patients in Tehran, Iran. Iran J Pharm Sci 2010; 6:125-32. https://doi.org/10.4103/0975-7406.99058

12. Obiazi HAK, Ekundayo AO, Ukwandu NCD. Prevalence and antibiotic susceptibility pattern of Staphylococcus 
aureus from clinical isolates grown at 37 and $44^{\circ} \mathrm{C}$ from Irrua, Nigeria. African J Microbiol Res 2007; 1:57-60. https://doi.org/10.4103/0972-5229.58542

13. Ojulong J, Mwambu TP, Joloba M, Bwanga F, KadduMulindwa DH. Relative prevalence of methicilline resistant Staphylococcus aureus and its susceptibility pattern in Mulago Hospital, Kampala, Uganda. Tanzan J Health Res 2009; 11:149-53. https://doi.org/10.4314/thrb.v11i3.47703

14. Dibah S, Arzanlou M, Jannati E, Shapouri R. Prevalence and antimicrobial resistance pattern of methicillin resistant Staphylococcus aureus (MRSA ) strains isolated from clinical specimens in Ardabil, Iran. Iran J Microbiol 2014; 6:163-8. PMID: 25870749

15. Funke G, Funke-Kissling P. Performance of the new VITEK 2 GP card for identification of medically relevant Gram-positive cocci in a routine clinical laboratory. J Clin Microbiol 2005; 43:84-8. https://doi.org/10.1128/JCM.43.1.84-88.2005

16. Omuse G, Kabera B, Revathi G. Low prevalence of methicillin resistant Staphylococcus aureus as determined by an automated identification system in two private hospitals in Nairobi, Kenya: a cross sectional study. BMC Infect Dis. 2014; 14:669. https://doi.org/10.1186/s12879-014-0669-y

17. Wertheim HFL, Vos MC, Boelens HAM, Voss A, Vandenbroucke-Grauls CMJE, Meester MHM. Low prevalence of methicillin-resistant Staphylococcusaureus (MRSA) at hospital admission in the Netherlands: the value of search and destroy and restrictive antibiotic use. $\mathbf{J}$ Hosp Infect. 2004; 56:321-5. https://doi.org/10.1016/j.jhin.2004.01.026

18. Crowley E, Bird P, Fisher K, Goetz K, Boyle M, Benzinger MJJ. Evaluation of the VITEK 2 gram positive (GP) microbial identification test card: collaborative study. J AOAC Int 2012; 95:1425-32. https://doi.org/10.5740/jaoacint.CS2011_17

19. Joshi S. Methicillin resistant Staphylococcus aureus (MRSA) in India: prevalence and susceptibility pattern. Indian J Med Res 2013; 137:363-9. PMID: 23563381

20. Arianpoor A, Estaji F, Naderinasab M, Askari E. Antimicrobial susceptibility pattern of Staphylococcus aureus Isolates against newly marketed antibiotics. J Ayub Med Coll Abbottabad 2015; 3:3-6. https://doi.org/10.4314/pamj.v8i1.71050
21. Rayner C, Munckhof WJ. Antibiotics currently used in the treatment of infections caused by Staphylococcus aureus. Intern Med J 2005; 35 (Suppl 2):3-16. https://doi.org/10.1111/j.1444-0903.2005.00976.x

22. Sanchez Garcia M, De la Torre MA, Morales G, Pelaez B, Tolon MJ, Domingo S, et al. Clinical outbreak of linezolid-resistant Staphylococcus aureus in an intensive care unit. JAMA 2010; 303(22):2260-4 https://doi.org/10.1001/jama.2010.757

23. Panlilio AL, Culver DH, Gaynes RP, Banerjee S, Henderson TS, Tolson JS. Methicillin-resistant Staphylococcus aureus in US hospitals, 1975-1991. Infect Control Hosp Epidemiol 1992; 13:582-6. https://doi.org/10.1086/646432

24. Latif S, Anwar MS, Chaudary NA. Susceptibility Pattern of Nosocomial Methicillin Resistant Staphylococcus aureus (MRSA) Isolates to Vancomycin and other AntiStaphylococcal Antibiotics. Biomedica 2000; 16:32-517. https://doi.org/10.7860/JCDR/2013/6750.3463

25. Bukhari MH, Iqbal A, Khatoon N, Iqbal N, Naeem S, Qureshi G R, et al. A laboratory study of susceptibility of methicillin resistant Staphylococcus aureus (MRSA). Pak J Med Sci 2004; 20:229-33.

26. Saikia L, Nath R Choudhary B, Sarkar M. Prevalence and antimicrobial susceptibility pattern of methicillin resistant Staphylococcus aureus in Assam. Indian J Crit Care Med 2009; 13:156-8. https://doi.org/10.4103/0972-5229.58542

27. Kumari N, Mohapatra TM, Singh YI. Prevalence of Methicillin-Resistant Staphylococcus aureus (MRSA) in a Tertiary-Care Hospital in Eastern Nepal. J Nepal Med Assoc 2008; 47(170):53-6

28. Dominique S, Blanc, et al. Epidemiology of methicillin resistant Staphylococcus aureus:results of a nation- wide survey in Switzerland. Swiss Med wkly 2002; 132:223-9. PMID: 12087488

29. Vandenbroucke-Grauls C. Epidemiology of staphylococcal infections-a European perspective. JAC 1994; 6:67-70.

30. Begum ES, Anbumani N, Kalyani J, Mallika M. Prevalence and antimicrobial susceptibility pattern of Coagulase-negative Staphylococcus. Int J Med Public Health 2011; 1(4):59-62. PMID: 26885328

31. Perveen I, Majid A, Knawal S, Naz I, et al. Prevalence and antimicrobial susceptibility pattern of Methicillin-Resistant Staphylococcus aureus and coagulase-negative staphylococci in Rawalpindi, Pakistan. Br J Med Med Res 2013; 3(1):198-209.https://doi.org/10.4103/0972-5229.58542 